\title{
RISK FACTORS OF PRETERM BIRTH AND LOW BIRTH WEIGHT NEONATES AMONG ROMA AND NON-ROMA MOTHERS
}

\author{
Jana Diabelková1, Kvetoslava Rimárová1, Peter Urdzík², Erik Dorko', Andrea Bušová1 \\ ${ }^{1}$ Department of Public Health and Hygiene, Faculty of Medicine, Pavol Jozef Šafárik University in Košice, Košice, Slovak Republic \\ ${ }^{2}$ Department of Gynaecology and Obstetrics, Faculty of Medicine, Pavol Jozef Šafárik University in Košice and Louis Pasteur University \\ Hospital, Košice, Slovak Republic
}

\begin{abstract}
SUMMARY
Objective: This study analyses the differences in birth outcomes between Roma and non-Roma mothers and investigates the potential causes of such differences.

Methods: We conducted a retrospective cohort study of 1,989 non-Roma and 799 Roma mothers who gave birth in 2014 and 2015 at the Gynaecology and Obstetrics Clinic of Louis Pasteur University Hospital in Košice. Data on mothers and new-born infants have been obtained from the birth book and from the reports on mothers at childbirth. For low birth weight we considered the weight of a new-born weighing less than 2,500 grams and as for premature birth we referred to childbirth before pregnancy week 37 . The file was split by ethnicity and statistically processed in IBM SPSS Statistics 21.0.

Results: Our results confirmed a lower birth weight among Roma children (-365.4 grams, $p<0.001)$. The shorter gestation age and higher risk of premature birth were not statistically significant regarding Roma children. Based on the characteristics of Roma mothers, they are at higher risk of giving birth as minor $(O R=23.64 ; 95 \% \mathrm{Cl}=15.29-36.54 ; p<0.001)$, as single mothers $(\mathrm{OR}=7.13 ; 95 \% \mathrm{Cl}=5.80-8.76 ; \mathrm{p}<0.001)$, with basic education or lack of education $(\mathrm{OR}=141.31 ; 95 \% \mathrm{Cl}=100.47-198.76 ; p<0.001)$. They also have a higher risk of smoking during pregnancy $(\mathrm{OR}=23.84 ; 95 \% \mathrm{Cl}=18.06-31.49 ; \mathrm{p}<0.001)$; drinking alcohol $(\mathrm{OR}=11.71 ; 95 \% \mathrm{Cl}=3.36-40.90 ; \mathrm{p}<0.001)$ and taking drugs $(\mathrm{OR}=8.70$; $95 \% \mathrm{Cl}=1.81-42.02 ; \mathrm{p}<0.001)$. Roma women attended gynaecologists more rarely.

Conclusion: It is therefore important to support the work of community health workers and stimulate collaboration between community health professionals, paediatricians and gynaecologists to overcome institutional barriers in maternity and child care for mothers living in Roma settlement.
\end{abstract}

Key words: birth outcomes, birth weight, preterm birth, Roma infants, risk factors

Address for correspondence: K. Rimárová, Department of Public Health and Hygiene, Faculty of Medicine, P. J. Šafárik University, Šrobárova 2, 041 80, Košice, Slovak Republic. E-mail: kvetoslava.rimarova@upjs.sk

https://doi.org/10.21101/cejph.a5273

\section{INTRODUCTION}

The Roma people (Romanies, wrongly called Gypsies) are the most numerous ethnic minority in Central and Eastern Europe (1). Roma families have been probably a part of the population of today's Slovak territory for six centuries. In addition to Romania, Bulgaria and Hungary, the most numerous Roma community in Europe lives in the Slovak Republic. The Slovak Republic has the second largest estimated proportion of Roma (9.17\%) after Bulgaria (10.33\%) (2). Spatial distribution of Roma in Slovakia is markedly uneven. Most Roma live in settlements and peripheries of villages and towns. About one quarter of all Slovak Roma live in settlements, most of which are located in the poorer eastern parts of the country (3).

From the demographic point of view, the Roma are characterized by higher birth rates and higher mortality depending on ethnic integration into society. Romanies have a progressive type of age structure with a high density of child population and a low density of older people. These differences are the reason of the low aging index (3).
A closer look at the health of Roma population shows that in general they have poorer health than the national average. The process of social exclusion and marginalization, a low level of hygiene as a result of insufficient infrastructure, polluted and devastated environment, lower education, unhealthy eating habits and nutrition, increasing alcohol consumption and smoking rates during pregnancy, and increasing drug addiction are factors that are reflected in the health of Roma communities (1-8).

The Roma population differs from the majority in the way of life, standard of living and level of education and also in their reproductive behaviour (9). For a Roma woman, children have the highest value. She gives birth as soon as she is mature. As a result, Roma practices are in conflict with legislation. Roma women bring children into the world during their entire reproduction period. Through a man's eyes a woman is valued mainly by giving birth to children. A barren woman is a shame for a Roma man, and the shame then falls not only on her, but also on her relatives. A large number of births are recorded mainly in the most vulnerable and socially disadvantaged families $(10,11)$. 
Antenatal care visits are not a matter of course for the Roma. The isolation of settlements in which many Roma communities live also causes considerable misinformation about accessibility and rights to health care and their distrust in official health institutions. Due to the difficult access to health care caused by various factors (large distance of the health centre, insufficient hygiene, discrimination against Roma shown in health care institutions, lack of access to prescribed medication due to financial reasons, etc.) a part of the Roma population visits the doctor only in serious health conditions (12-18). However, the Roma population prefers births in a hospital or in a healthcare institution. According to Roma rituals, the birth of the child is not to be given in the family environment, because the house or household loses its purity and immaculacy. However, the phenomenon of mothers escaping after delivery from the hospital mainly persists among mothers from segregated settlements. Roma mothers come back to their children after a few days. The most common reason for these escapes is the jealousy of the man or the care for the other children in the settlement $(8,11)$.

Due to the lifestyle and the environment in which they live, the Roma women are at greater risk of having complications during pregnancy. Data from the Czech Republic, Hungary and Slovakia indicate that abortions, low birth rates, premature birth rates and infant mortality are more common in Roma than nonRoma populations $(1,2,4,8,19,20)$.

The aim of our study is therefore to describe and compare the current state of reproductive health and neonatal indicators among the Roma and non-Roma ethnic groups living in Eastern Slovakia.

\section{MATERIALS AND METHODS}

\section{Setting and Subjects}

The research of gynaecological and neonatal indicators was carried out in the years 2014-2015 in Eastern Slovakia. The collection of data took place in the context of daily work and academic and research activity at the Faculty of Medicine of Pavol Jozef Šafárik University and the Department of Gynaecology and Obstetrics of the Louis Pasteur University Hospital in Košice. This hospital is the East Slovakian centre for low birth weight and premature birth and this is the reason why there is also a higher concentration of mothers at risk. The implementation of the research was approved by the ethics committee assuming that its implementation is being in line with valid legislation and the protection of the respondents' personal data.

\section{Measurements}

Basic medical records on mothers (socioeconomic anamnesis, behavioural factors, health condition, and course of pregnancy) and basic data on new-borns (birth weight, length, Apgar score) were collected from the medical record documentation. The ethnicity of Roma mothers was confirmed with using two principles. We could identify Roma mother by asking her, if in the family she lives with, know or speak Roma language. Second system of the ethnicity identification was based on the principle of permanent address, when all citizens living in the neighbourhood Lunik 9 (area in the Košice-city) are exclusively of Roma ethnicity. The data have been reported from the birth book and from the reports on mothers at childbirth. From the records regarding mothers, we were primarily interested in age, education, marital status, visits to antenatal care, but also risk behaviour such as smoking, alcohol and drug use. The age of mothers at the time of delivery was calculated on the basis of the date of birth indicated in the reports on mothers at childbirth and delivery date. When observing the use of tobacco, in our file we considered for a smoker a woman smoking at least one cigarette a day during the pregnancy. For alcohol consumer we considered every woman who consumed 15 grams of alcohol a day. This corresponds to 0.5 litre of 12 -degree beer, or 0.31 of wine or $0.5 \mathrm{dl}$ of spirits. Women with multiple pregnancy who are at higher risk of preterm birth and whose new-born babies are also more likely to be born with a lower birth weight were excluded from the study. Mothers of new-born babies with birth weight not reaching 1,500 grams (very low birth weight) were also excluded from the study. Low birth weight has been defined as a birth weight of less than 2,500 grams.

\section{Statistical Analysis}

Data on babies and new-borns were included in the database created in IBM SPSS Statistics 21.0. Primary characters (obtained directly from the reports on mothers at childbirth) and transformed characters (recategorized) were used to process the data. The analysis contains significant findings linked to the obtained empirical data when the vast majority of the findings was statistically significant. Statistical analysis of the comparison was performed using several statistical methods in IBM SPSS Statistics 21.0. We compared the replies in the databases inter-ethnically with the expression of basic frequency analysis. For comparison of nominal values of statistical significance, we used a chi-square test by Mantel Haenszel. Continuous variables were processed by comparing the arithmetic mean by Student's t-test. To compare the frequency of social and anamnestic factors, the odds ratio (OR) was used as the ratio of a certain factor present in the Roma and non-Roma populations.

\section{RESULTS}

The final data set consisted of 2,788 singleton births, of whom 799 (28.7\%) occurred among Roma women. The distribution of socioeconomic characteristics and behaviours is shown in Table 1. The most of Roma women in our set were 18 to 19 years old. Up to 179 Roma women $(22.4 \%)$ were under the age of 18 , in contrast to the majority population with only 24 female $(1.2 \%)$ minors. Age distribution among mothers ranged from 14 to 45 years. Our survey confirmed the lower education level of Roma mothers $(\mathrm{p}<0.001)$, having only primary education $(86.4 \%)$. During the pregnancy, $49.3 \%$ of Roma women admitted smoking. For non-Roma women, the percentage of smokers was only $3.9 \%$ $(\mathrm{p}<0.001)$. Although alcohol consumption during pregnancy was relatively low $(0.7 \%)$, results regarding alcohol use are statistically significant $(\mathrm{p}<0.001)$ and point to the higher alcohol consumption in the Roma group ( $1.9 \%$ vs. $0.2 \%)$. Only 9 mothers $(0.4 \%)$ admitted the use of drugs during pregnancy, but 7 of them were Roma women. Among 48.7\% of Roma women, the pregnancy was diagnosed by gynaecologist only after the first trimester. Regard- 
Table 1. Socio-demographic characteristics of study participants $(N=2,788)$

\begin{tabular}{|c|c|c|c|c|}
\hline Variables & $\begin{array}{c}\text { All } \\
\mathrm{n}(\%)\end{array}$ & $\begin{array}{l}\text { Roma } \\
\mathrm{n}(\%)\end{array}$ & $\begin{array}{c}\text { Non-Roma } \\
\mathrm{n}(\%)\end{array}$ & p-value \\
\hline \multicolumn{5}{|l|}{ Maternal age group } \\
\hline$\leq 18$ & $203(7.3)$ & $179(22.4)$ & $24(1.2)$ & \multirow{3}{*}{$<0.001$} \\
\hline $19-34$ & $2,127(76.3)$ & $563(70.5)$ & $1,564(78.6)$ & \\
\hline$>34$ & $458(16.4)$ & $57(7.1)$ & $401(20.2)$ & \\
\hline \multicolumn{5}{|l|}{ Marital status } \\
\hline Single & $807(36.4)$ & $435(69.8)$ & $372(23.3)$ & \multirow{3}{*}{$<0.001$} \\
\hline Married & $1,373(61.9)$ & $182(29.2)$ & $1,191(74.6)$ & \\
\hline Divorced/widowed & $39(1.8)$ & $6(1.0)$ & $33(2.1)$ & \\
\hline \multicolumn{5}{|l|}{ Education } \\
\hline Primary & $576(27.2)$ & $510(86.4)$ & $66(4.3)$ & \multirow{3}{*}{$<0.001$} \\
\hline High school & $835(39.4)$ & $75(12.7)$ & $760(49.7)$ & \\
\hline University & $708(33.4)$ & $5(0.8)$ & $703(46.0)$ & \\
\hline \multicolumn{5}{|c|}{ Smoking during pregnancy } \\
\hline Yes & $433(17.0)$ & $362(49.3)$ & $71(3.9)$ & \multirow{2}{*}{$<0.001$} \\
\hline No & $2,112(83.0)$ & $372(50.7)$ & $1,740(96.1)$ & \\
\hline \multicolumn{5}{|c|}{ Alcohol consumption during pregnancy } \\
\hline Yes & $17(0.7)$ & $14(1.9)$ & $3(0.2)$ & \multirow{2}{*}{$<0.001$} \\
\hline No & $2,528(99.3)$ & $720(98.1)$ & $1,808(99.8)$ & \\
\hline \multicolumn{5}{|c|}{ Drug consumption during pregnancy } \\
\hline Yes & $9(0.4)$ & $7(1.0)$ & $2(0.1)$ & \multirow{2}{*}{$<0.001$} \\
\hline No & $2,536(99.6)$ & $727(99.0)$ & $1,809(99.6)$ & \\
\hline \multicolumn{5}{|c|}{ First visit of gynaecologist } \\
\hline 1st trimester & $2,143(78.4)$ & $387(51.3)$ & $1,756(88.8)$ & \multirow{2}{*}{$<0.001$} \\
\hline Later & $589(21.6)$ & $367(48.7)$ & $222(11.2)$ & \\
\hline \multicolumn{5}{|c|}{ Visits to prenatal counselling } \\
\hline$<8$ weeks & $1,232(45.1)$ & $560(74.3)$ & $672(34.0)$ & \multirow{2}{*}{$<0.001$} \\
\hline$\geq 8$ weeks & $1,500(54.9)$ & $194(25.7)$ & $1,306(66.0)$ & \\
\hline
\end{tabular}

values in bold are statistically significant

Table 2. OR of selected risk factors for reproductive results among Roma mothers

\begin{tabular}{|l|c|c|c|}
\hline Variables & OR & $95 \% \mathrm{Cl}$ & $\mathrm{p}$-value \\
\hline Age $<18$ years vs. others & 23.6 & $15.3-36.5$ & $<0.001$ \\
\hline Non-married vs. married & 7.1 & $5.8-8.8$ & $<0.001$ \\
\hline Education basic vs. higher & 141.3 & $100.5-198.8$ & $<0.001$ \\
\hline Smoking during pregnancy yes/no & 23.8 & $18.1-31.5$ & $<0.001$ \\
\hline Alcohol consumption during pregnancy yes/no & 11.7 & $3.4-40.9$ & $<0.001$ \\
\hline Drug consumption during pregnancy yes/no & 8.7 & $1.8-42.0$ & $<0.001$ \\
\hline First visit of gynaecologist later/1st trimester & 7.5 & $6.1-9.2$ & $<0.001$ \\
\hline Visits to prenatal counselling <8/more & 5.6 & $4.7-6.8$ & $<0.001$ \\
\hline
\end{tabular}

values in bold are statistically significant

ing non-Roma women group, it was $11.2 \%$ of women $(\mathrm{p}<0.001)$ who visited the doctor while pregnant for the first time only after the first trimester. Most of the mothers visited the antenatal care eight times, so we divided the set into two groups - the mothers who visited the doctor less than 8 times and the group of mothers who visited the doctor 8 times and more. Then we compared the groups inter-ethnically. Up to $74.3 \%$ of Roma women visited the doctor during pregnancy less than 8 times, while only $34 \%$ of non-Roma women visited the antenatal care less than 8 times $(\mathrm{p}<0.001)$ (Table 1).

Roma women had a higher risk regarding all of our potential risk factors. For the highest risk was considered to be education where Roma women had a 141.3 higher risk that their highest level of completed education would be basic $(p<0.001)$ (Table 2$)$. 
Table 3. Bivariate model of mean birth weight differences of neonates related to mother's ethnicity and socioeconomic characteristics

\begin{tabular}{|l|c|c|c|c|c|}
\hline \multirow{2}{*}{ Variables } & \multirow{2}{*}{ Mean difference } & \multirow{2}{*}{ SD } & \multicolumn{2}{|c|}{$95 \% \mathrm{Cl}$} & \multirow{2}{*}{$\mathrm{p}$-value } \\
\cline { 4 - 6 } & & & $\mathrm{UL}$ & -321.5 & $<0.001$ \\
\hline Roma vs. non-Roma & -365.4 & 22.40 & -409.4 & -276.1 & $<0.001$ \\
\hline Age < 18 years vs. others & -355.0 & 40.20 & -433.9 & -262.6 & $<0.001$ \\
\hline Non-married vs. married & -309.2 & 23.70 & -355.7 & -370.5 & $<0.001$ \\
\hline Education basic vs. higher & -421.1 & 25.80 & $-471.7)$ & -489.2 & $<0.001$ \\
\hline Smoking during pregnancy yes/no & -444.2 & 28.00 & -449.2 & -133.1 & 0.003 \\
\hline Alcohol consumption during pregnancy yes/no & -398.5 & 135.30 & -663.9 & -49.1 & 0.026 \\
\hline Drug consumption during pregnancy yes/no & -413.5 & 185.90 & -778.0 & 279.7 & $<0.001$ \\
\hline First visit of gynaecologist later/1st trimester & 229.6 & 25.50 & 179.5 & -225.5 & $<0.001$ \\
\hline Visits to prenatal counselling <8/more & -266.3 & 20.81 & -307.1 & 2 \\
\hline
\end{tabular}

SD - standard deviation; Cl - confidence interval; LL - lower limit; UL - upper limit; values in bold are statistically significant

Table 4. Birth outcomes in Roma and non-Roma infants $(N=2,788)$

\begin{tabular}{|l|c|c|c|c|}
\hline Variables & All & Roma & Non-Roma & p-value \\
\hline Birth weight (g) mean (SD) & $3,145.2(559.7)$ & $2,884.5(486.4)$ & $3,250.0(553.1)$ & $<0.001$ \\
\hline Birth length (cm) mean (SD) & $48.7(2.8)$ & $47.2(2.7)$ & $49.2(2.7)$ & $<0.001$ \\
\hline Gestational age (weeks) mean (SD) & $38.8(1.8)$ & $38.7(1.7)$ & $38.8(1.8)$ & 0.187 \\
\hline Apgar score in 1st minute, mean (SD) & $9.0(1.9)$ & $8.9(2.0)$ & $9.0(1.8)$ & 0.171 \\
\hline Apgar score in 5th minute, mean (SD) & $9.5(1.6)$ & $9.5(1.6)$ & $9.5(1.6)$ & 0.543 \\
\hline Low birth weight (<2,500 g), $\mathrm{n}(\%)$ & $326(11.7)$ & $154(19.3)$ & $172(8.6)$ & $<0.001$ \\
\hline Preterm birth (<37 weeks), $\mathrm{n}(\%)$ & $273(9.8)$ & $77(9.6)$ & $196(9.9)$ & 0.462 \\
\hline Apgar score in 1st minute (<7), $\mathrm{n}(\%)$ & $309(11.1)$ & $104(13.0)$ & $205(10.3)$ & 0.024 \\
\hline Apgar score in 5th minute (<7), $\mathrm{n}(\%)$ & $119(4.3)$ & $43(5.4)$ & $76(3.8)$ & $\mathbf{0 . 0 4 3}$ \\
\hline
\end{tabular}

values in bold are statistically significant

The selected risk factors in life of the mothers caused differences in the weight of new-borns ranging from 266.3 to 444.2 grams. The most significant differences in the average weight of new-borns were related to smoking during pregnancy. Mothers who smoked during pregnancy gave birth to children weighing at average 444.2 grams less $(\mathrm{p}<0.001)$ (Table 3$)$.

Roma children were born weighing 365.4 grams less and measuring $2.0 \mathrm{~cm}$ less than non-Roma children $(\mathrm{p}<0.001)$. They were born with a low birth weight more frequently. However, it is interesting that the differences in pregnancy length and prevalence of premature birth have not been confirmed as statistically significant. Thus, Roma children were born in the same gestational week but were smaller in general. Differences in average Apgar scores were not statistically significant. However, with a lower statistical significance $(\mathrm{p}<0.05)$, a higher prevalence of Roma children achieving Apgar scores lower than 7 (Table 4) in the 1st and the 5th minute was confirmed.

\section{DISCUSSION}

This study in a representative community sample of births found striking ethnic differences in most outcomes studied, and in most socio-demographic characteristics. The primary aim of this study was to identify possible risk factors associated with low birth weight and preterm birth, with a special emphasis on similarities and differences among Roma and non-Roma women. Our research reinforces earlier findings and offers additional insights into the impact of social and behavioural factors contributing to poor birth outcomes among Roma and non-Roma women.

Our results confirm the high representation of Roma mothers under the age of 18. Roma women were more than 23 times more likely to give birth as minors $(\mathrm{p}<0.001)$. Children born to a minor mother weighed at average 355.0 grams less $(\mathrm{p}<0.001)$.

Mothers living without a partner are socially more vulnerable and such a marital status is a risk factor for gynaecological and neonatal health indicators. Vaňo and Mészáros (3) estimate that the number of children born to single women depends on the degree of integration. In case of integrated Roma, the authors estimate the proportion of extramarital births to $19 \%$, in segregated sites $39 \%$ and in partially segregated sites up to $44 \%$. In our survey, up to $69.8 \%$ of Roma women were single. Regarding the mothers from majority group, $23.3 \%$ of women were single $(p<0.001)$. New-borns of single mothers were born with the birth weight of 309.2 gram less, while in a similar Czech study (1), the difference was 232 grams. We cannot say explicitly how many children born out of wedlock are actually born to single mothers and how many children are born to the 
couples living in a non-marital relationship but either situation is nowadays nothing unusual.

Roma women are largely uneducated in the field of planned parenthood, which subsequently results in unwanted pregnancies among adolescent girls $(6,9,12)$. According to Dumitru et al. (12), in the era of computer tomography and laparoscopy, some Romanian Roma girls commonly use contraceptive methods such as vaginal rinsing with vinegar, lemon juice or Coca-Cola before or after sexual intercourse.

From the point of view of economic mobility and social selfrealization, the Roma unfortunately perceive education as unnecessary value. For Roma women in the research of Rimárová (8), basic elementary education is predominant (92.29\%), which is also confirmed by our results $(86.4 \%)$. These results also correspond to the results of the Czech (1) and Hungarian studies $(2,4)$. For many groups of Roma women, the only extended period of integration into society is compulsory schooling. After its completion they remain permanently excluded from various spheres of public life and enclosed in the segregated areas and in the domestic sphere. Under the circumstances, the question is how to make the most effective use of the period of integration of Roma women into the education system not only for education but also for preparation for life.

Several studies indicate low education as a risk factor of low birth weight (21-25). In Iran, the prevalence of low birth weight regarding non-educated women was $16.9 \%$ and with a rising level of education it dropped to $5.4 \%(\mathrm{p}<0.008)$. A study taken in Bangladesh shows up to $32.7 \%$ of the prevalence of low birth weight among neonates whose mothers did not receive education, while in case of high school students the prevalence of low birth weight was only $1.8 \%$ (21). In another study, Astone et al. (24) point to the lower average weight of neonatal mothers with lower education. Children of mothers with higher education had a 82 grams higher average birth weight than those whose mothers had completed a lower level of education. The following study with the same research object points to an even greater difference in neonatal weight. The birth weight of children of mothers with lower education was 123 grams lower than that of mothers with higher education (25).

Our survey confirmed the lower education level of Roma mothers $(\mathrm{p}<0.001)$, having mainly primary education $(86.4 \%)$. In the group of Roma women, only 5 mothers had university education. Low education is the reason for the high unemployment of the Roma. Non-Roma women were predominantly secondary school $(49.7 \%)$ and college graduates $(46.0 \%)$. There were huge differences in the educational level of Roma and non-Roma women. In case of Roma new-borns, they were more than 141 times more likely $(p<0.001)$ to be born to mothers with elementary education, while the birth weight of children born to mothers with elementary education was at average 421.1 grams lower $(\mathrm{p}<0.001)$. In the Czech study (1), the difference in the average birth weight of new-borns born to a mother with basic and university education was 322 grams.

A higher level of education is associated with a longer pregnancy $(26,27)$ which is also confirmed by our results, but with no statistical significance. Roma females gestational age was 38.7 weeks and non-Roma females had gestational age 38.8 weeks with no statistical significance. Also, the higher risk of premature birth among low-educated women has not been confirmed in our set.
According to the cross-sectional study conducted in Slovakia involving 452 Roma and 403 non-Roma respondents, men and women living in Roma settlements are more likely to smoke daily and are more likely to be strong smokers than the majority population $(1,2)$. In the study by Janevic et al. (28) who observed 410 pregnant Roma women, up to $36.1 \%$ of them smoked during the pregnancy. More frequent smoking during pregnancy among Roma women is confirmed by Bobak et al. (1) and Balázs et al. (2). In the survey by Širvinskiené et al. (29), 14.8\% of 514 mothers admitted smoking during pregnancy. Our survey shows even more unfavourable results, with up to $49.3 \%$ of Roma women admitting that they were smoking during pregnancy. Our results are similar to the results of Rimárová (8), who evaluated behaviour of 4,950 mothers, of whom 1,516 were Roma and $41.86 \%$ of them were smokers. In our study, the difference between the average weight of children of the smoker and non-smoker was 444.23 grams $(p<0.001)$ in favour of children of non-smokers while smokers had a higher risk $(\mathrm{OR}=1.49 ; \mathrm{p}<0.05)$ to give birth prematurely.

Alcohol use is not constant in Roma communities. However, especially after receiving social benefits, alcohol is consumed in large quantities for several days. The HepaMeta study (7) did not find differences in alcohol consumption among Roma and nonRoma men. However, Roma women reported less frequent recent drinking of alcohol and excessive drinking of 6 or more doses of alcohol on one occasion. In our set $1.9 \%$ of Roma respondents admitted alcohol consumption during pregnancy. The results of Rimárová (8) show that $9.34 \%$ of Roma women drink alcohol. Data on alcohol use seems to be strongly influenced by dissimulation and appears to be falsely lower than real ones.

Another risk factor is drug abuse. Particularly widespread among young people is the inhalation of volatile substances such as glue or toluene, which leads to permanent brain damage. Although men are mainly among the users, this phenomenon is also related to women. During pregnancy, $1.0 \%$ of the Roma women used drugs. In case of women, drug use in the Roma community is significantly more tabooed and condemned, so it is possible that there were women who decided to hide this fact.

A major problem related to reproductive health is that pregnant Roma women do not attend antenatal care (14-18). The future mother does not know the date of birth and therefore does not know when to expect the first symptoms of the childbirth. There are cases when the woman cannot even indicate the length of her pregnancy when she arrives at the maternity ward and the obstetrician does not know whether to expect a full-term pregnancy or a premature birth. Study conducted in 2011 on a sample of 454 Roma mothers confirmed that $35 \%$ of the respondents attended the antenatal care for pregnant women irregularly or not at all (30). The low participation of Roma mothers in antenatal care has been also confirmed by our results. Roma women were more than 7 times more likely to visit antenatal care later than in the first trimester of pregnancy. The unexpected result for us is that the mothers who attended antenatal care later than in the first trimester gave birth to babies weighing at average 229.6 grams more. Roma women have in comparison with non-Roma mothers more than 5 times higher risk of attending antenatal care less than 8 times. Mothers attending the antenatal care more rarely had children weighing at average 266.3 grams less. According to Filadelfiová and Porubänová (11), the first of the reasons why some Roma women do not go to regular check-ups is a pregnancy 
without any problems: "I did not need to go to the doctor as I had no problem". The second reason is the lack of information about such a possibility: "No one told me to go to an examination". An important role is also played by the spatial distance. Women do not have money to pay travel expenses or they have no way to get to the doctor. Some of the women without regular check-ups states that they have to take care for the other children and that prevents them from going to the doctor, or the lack of finance. The fear of a gynaecologist is only a very rare cause. However, it happens quite often that Roma women cannot specify the main reason why they do not go to a doctor during their pregnancy.

Roma children are more likely to be born prematurely and this is also related to a poor mothers' health style during pregnancy. Lower gestational age is a basic predisposition for lower birth weight, length, and also for the risk of neonatal immaturity. However, in our survey, the difference between the gestational week of Roma and non-Roma children was not significant.

In the group of Roma children, low birth weight is more common. Up to $19.3 \%$ of the monitored Roma children have low birth weight, whereas for the non-Roma population it is only $8.6 \%$. When weighing 9,040 new-borns in Hungary, a difference of 288.7 grams was seen among Roma and non-Roma children in favour of non-Roma children (2). In the study of Bobak et al. (1) conducted in the Czech Republic, where 10,326 new-borns were monitored, Roma children weighed 373 grams less. In our study, the difference between the birth weights of Roma and non-Roma children was 365.5 grams. The question remains open whether the indicator of low birth weight $(<2,500$ grams) should be valid also for Roma infants.

Considering effect of ethnic origin there are many studies showing "healthy migrant effect". The healthy migrant effect was confirmed among immigrants from Eastern Europe to the U.S., especially among women with lower level of education and those from the former Yugoslavia (31). On the other side Canadian study (32), which included 98,330 live births, examined the interaction between maternal education, foreign born status and pregnancy showing that foreign born status was associated with adverse birth outcomes in university-educated mothers, the opposite of the healthy migrant effect.

\section{Limitations of the Study}

Our cross-sectional study did not include all possible negative factors influencing pregnancy outcome. We did not follow the nutritional habits of pregnant females or possible effect of passive smoking as in other studies $(2,20)$.

\section{CONCLUSIONS}

Achieving good health for all the population is a shared responsibility that requires cooperation, synergy and partnership at all levels and between all the components of society. Knowledge and awareness of the Roma minority and its problems is the key to the social integration of this population. In our opinion, it is inevitable to start with a consistent collection of data and the creation of information databases on Roma. Their subsequent analysis can be considered as a prerequisite for obtaining a picture that is realistic or as close as possible to reality regarding the situation of the Roma population and for subsequent understanding not only of the needs but also of the possibilities of Roma participation in the formation of our society.

Our results regarding Roma children confirmed lower birth weight. Based on the characteristics of Roma mothers, they were in comparison to non-Roma mothers younger, single, had higher number of pregnancies, had only basic or lack of education, less often attended antenatal care, more often smoked, drank alcohol and took drugs during pregnancy. These data illustrate the link between the socioeconomic conditions in Roma settlements and the need for a subnational monitoring. The analysis of the pursued relations is to be understood as one of the possible ways of searching and learning, while communication with other relevant departments (ethnography, culture, history, etc.) is a prerequisite for a comprehensive understanding of character of the way of life of Roma citizens.

There are several actions that have the potential to reduce the differences in reproductive health. One of them is to support the work of community health workers and to stimulate cooperation between community health workers, paediatricians and gynaecologists in order to overcome the institutional barriers regarding mother and child care in Roma settlements. Another action could be the introduction of an intensive and long-term health promotion programme for adolescent Roma women focused on reproductive health, prenatal care and planned parenthood.

\section{Acknowledgements}

This work was supported by grants: KEGA No. 007UPJŠ-4/2018 and VEGA $1 / 0873 / 18$, VEGA 1/0011/14 of the Ministry of Education, Science, Research and Sport of the Slovak Republic and internal University Pavol Jozef Šafárik Project VVGS-2018-897. We thank also Directory Board of University Hospital in Košice for assistance with organization of samples collection at the hospital wards.

\section{Conflict of Interests}

None declared

\section{REFERENCES}

1. Bobak M, Dejmek J, Solansky I, Sram RJ. Unfavourable birth outcomes of the Roma women in the Czech Republic and the potential explanations: a population-based study. BMC Public Health. 2005;5:106. doi: 10.1186/1471-2458-5-106.

2. Balázs P, Rákóczi I, Grenczer A, Foley KL. Birth-weight differences of Roma and non-Roma neonates - public health implications from a population-based study in Hungary. Cent Eur J Public Health. 2014;22(1):24-8.

3. Vaňo B, Mészáros J. Reproductive behavior of the population in municipalities with low standard of living. Bratislava: INFOSTAT; 2004. (In Slovak.)

4. Balázs P, Rákóczi I, Grenczer A, Foley KL. Risk factors of preterm birth and low birth weight babies among Roma and non-Roma mothers: a population-based study. Eur J Public Health. 2013;23(3):480-5.

5. Gecková AM, Babinská I, Bobáková D, Veselská ZD, Bosáková L, Kolarčik P, et al. Socioeconomic characteristics of the population living in Roma settlements and their association with health and health-related behaviour. Cent Eur J Public Health. 2014 Mar;22 Suppl:S57-64.

6. Karadzhova P, Romanov K, Kamburova M. Reproductive health needs and access to health services among Roma women in district Pleven, Bulgaria. Eur J Public Health. 2015 Oct;25 Suppl 3:392.

7. Babinská I, Gecková AM, Jarčuška P, Pella D, Mareková M, Štefková G, et al. Does the population living in Roma settlements differ in physical activity, smoking and alcohol consumption from the majority population in Slovakia? Cent Eur J Public Health. 2014 Mar;22 Suppl:S22-7. 
8. Rimárová K. Overview of the results of studies on the health status of the minority Roma population in the area of child growth, the impact on pregnancy and the frequency of infectious diseases. In: Proceeding of scientific and special papers from structural fund of EU [Internet]. Košice: UPJŠ LF; 2013 [cited 2018 Aug 20]. p. 159-67. Available from: http://www.lf.upjs.sk/cemio/publikacie/Rimarova-Prehlad-UPJS2013. pdf. (In Slovak.)

9. Logar M, Pavlič DR, Maksuti A. Standpoints of Roma women regarding reproductive health. BMC Women's Health. 2015 Apr;15:38. doi: 10.1186/s12905-015-0195-0.

10. Hotchkiss DR, Godha D, Gage AJ, Cappa C. Risk factors associated with the practice of child marriage among Roma girls in Serbia. BMC Int Health Hum Rights. 2016 Feb;16:6. doi: 10.1186/s12914-016-0081-3.

11. Filadelfiová J, Porubänová S. Context and circumstances of selected aspects of health and reproductive health of Roma women. [Internet]. Bratislava: Institute for Labour and Family Research; 2012 [cited 2018 Aug 20]. Available from: https://www.ceit.sk/IVPR/images/IVPR/vyskum/2012/Filadelfiova/2259 porubanova filadelfiova.pdf. (In Slovak).

12. Dumitru, M, Chirea G, Punga A, Ciobotariu G, Boda D. Reproductive health and sexual behaviour among Roma communities in Romania: Madalina Dumitru. Eur J Public Health. 2014 Oct;24 Suppl 2:122.

13. Sedlecky K, Rašević M. Challenges in sexual and reproductive health of Roma people who live in settlements in Serbia. Eur J Contracept Reprod Health Care. 2015 Apr;20(2):101-9.

14. Földes ME, Covaci A. Research on Roma health and access to healthcare: state of the art and future challenges. Int J Public Health. 2012 Feb;57(1):37-9.

15. Colombini M, Rechel B, Mayhew SH. Access of Roma to sexual and reproductive health services: qualitative findings from Albania, Bulgaria and Macedonia. Glob Public Health. 2012;7(5):522-34.

16. Jarcuska P, Bobakova D, Uhrin J, Bobak L, Babinska I, Kolarcik P, et al. Are barriers in accessing health services in the Roma population associated with worse health status among Roma? Int J Public Health. 2013 Jun;58(3):427-34.

17. De Graaf P, Rotar Pavlič D, Zelko E, Vintges M, Willems S, Hanssens L. Primary care for the Roma in Europe: Position paper of the European forum for primary care. Slovenian J Public Health. 2016 Sept;55(3):218-24.

18. Bobakova D, Dankulincova Veselska Z, Babinska I, Klein D, Madarasova Geckova A, Cislakova L, et al. Differences between Roma and non-Roma in how social support from family and friends helps to overcome health care accessibility problems. Int J Equity Health. 2015 Jun;14:37. doi: 10.1186/s12939-015-0165-z.

19. Rosicova K, Madarasova Geckova A, van Dijk JP, Kollarova J, Rosic M, Groothoff JW. Regional socioeconomic indicators and ethnicity as predictors of regional infant mortality rate in Slovakia. Int J Public Health. 2011 Oct;56(5):523-31
20. Rambousková J, Dlouhý P, Křŕžová E, Procházka B, Hrnčířová D, Anděl M. Health behaviors, nutritional status, and anthropometric parameters of Roma and non-Roma mothers and their infants in the Czech Republic. J Nutr Educ Behav. 2009 Jan-Feb;41(1):58-64.

21. Dhar B, Mowlah G, Kabir DM. Newborn anthropometry and its relationship with maternal factors. Bangladesh Med Res Counc Bull. 2003 Aug;29(2):48-58.

22. Silvestrin S, Silva Ch, Hirakata VN, Goldani AA, Silveira PP, Goldani MZ. Maternal education level and low birth weight: A meta-analysis. J Pediatr. 2013 Jul-Aug;89(4):339-45.

23. Bendhari ML, Haralkar SJ. Study of maternal risk factors for low birth weight neonates: a case-control study. Int J Med Sci Public Health. 2015;4(7):987-90.

24. Astone NM, Misra D, Lynch C. The effect of maternal socio-economic status throughout the lifespan on infant birthweight. Paediatr Perinat Epidemiol. 2007 Jul;21(4):310-8

25. Jansen PW, Tiemeier H, Looman CW, Jaddoe VW, Hofman A, Moll HA, et al. Explaining educational inequalities in birthweight: the Generation R Study. Paediatric and Perinatal Epidemiology. 2009 May;23(3):216-28.

26. Auger N, Leduc L, Naimi AI, Fraser WD. Delivery at term: impact of university education by week of gestation. J Obstet Gynaecol Can. 2016 Feb;38(2):118-24.

27. Prunet C, Delnord M, Suarel-Cubizolles MJ, Goffinet F, Blondel B. Risk factors of preterm birth in France in 2010 and changes since 1995: results from the French National Perinatal Surveys. J Gynecol Obstet Hum Reprod. 2017 Jan;46(1):19-28.

28. Janevic T, Osypuk T, Stojanovski K, Jankovic J, Gundersen D, Rogers M. Associations between racial discrimination, smoking during pregnancy and low birthweight among Roma. Eur J Public Health. 2017 Jun;27(3):410-15.

29. Širvinskienė G, Žemaitienė N, Jusienėc R, Šmigelskasa K, Veryga A, Markūnienèd E. Smoking during pregnancy in association with maternal emotional well-being. Medicina. 2016;52(2):132-38.

30. Šupínová M, Frčová B, Benyusová V, Bielik U. Extramural births in the context of reproductive health in socially deprived and excluded populations. Cent Eur J Nurs Midw. 2014;5(3):99-104.

31. Janevic T, Savitz DA, Janevic M. Maternal education and adverse birth outcomes among immigrant women to the United States from Eastern Europe: A test of the healthy migrant hypothesis. Soc Sci Med. 2011;73(3):429-35.

32. Auger N, Luo Z, Platt RW, Daniel M. Do mother's education and foreign born status interact to influence birth outcomes? Clarifying the epidemiological paradox and the healthy migrant effect. J Epidemiol Community Health. 2008;62(5):402-9.

Received December 5, 2017

Accepted in revised form August 20, 2018 